\title{
Digital Literacy of Flemish Youth: How do they handle online content risks? ${ }^{1}$
}

\author{
SOFIE VANDONINCK, LEEN D'HAENENS \\ and VERÓNICA DONOSO
}

E-Mail: sofie.vandoninck@soc.kuleuven.be; leen.dhaenens@soc.kuleuven.be; veronica.donoso@soc.kuleuven.be

\section{Abstract}

The internet offers adolescents a huge window of opportunities, but these opportunities are not always exempt from risks. Indeed, many young people are nowadays confronted with spam, gruesome or violent images and content including pornography, drugs, racism, and even suicide. We surveyed 815 Flemish 15- to 19-year-olds about the online risks they (may) have been confronted with and on how they cope with these risks. We controlled for digital literacy levels, socio-demographics and personality traits. Interestingly, our research shows that not only adolescents with a high level of internet literacy but also those with lower internet literacy levels, such as youths enrolled in vocational education, tend to be more frequently exposed to online risks. Also worthwhile noting is the fact that a high level of self-confidence positively correlates with exposure to risky online content. In general, adolescents do not consult anybody when it comes to coping with risks and negative experiences online. However, a good parent-child relationship pays off as kids with a good parental relationship encounter aggressive, sexual or value-based content less frequently.

Keywords: online risks, content risks, coping strategies, adolescents, digital literacy

\section{Introduction}

Internet use by young people and children is a theme that increasingly receives more research attention. Recent comparative European research shows that $71 \%$ of all Belgian children search the internet (European Commission, 2008). In Flanders, $86 \%$ of the 9 - to 12 -year-olds and $96 \%$ of the 13- to 18-year-olds make use of the internet. From 11 years onwards, young people search the net daily. We observe that boys go online more often than girls. Boys use the internet on average 8.8 times a week, 
girls 6.1 times a week (Vandercammen, 2006). In comparison with other EU countries, the internet use of children in Belgium can be considered as "medium" (between $65 \%$ and $85 \%$ ) (Tsatsou, Pruulmann-Vengerfeldt and Murru, 2009).

As far as online opportunities are concerned, we find that in most EU countries, including Belgium, the majority of the children know how to make use of both the educational and the informative potential of the internet. The internet is also broadly used for entertainment, social networks and sharing experiences with others. However, when it comes to more complex applications which require active participation and creative input from the user, most children do not really engage in this type of online activities (Livingstone and Helsper, 2007).

Contrary to what most adults might expect, not all children and adolescents are equally capable and fluent in using the internet. Just as with adults, digital skills among youngsters are not equally distributed (Van Dijk, 2006). As a matter of fact, children living in higher socio-economic families and boys enjoying a better quality of access to the internet, go online more frequently and seem to benefit more from the online opportunities (Livingstone and Helsper, 2007).

Young people are encouraged to use the internet, because they are told that digital skills are crucial in order to be successful in the information society. Nevertheless, research has shown that more frequent use of online content is related to more exposure to online risks, and this statement preoccupies policy makers, schools, parents and other stakeholders (Livingstone and Helsper, 2009). Finding the right balance between accessing online opportunities and exposure to online risks remains a challenge. It does not seem effective to deny online risks, nor to act restrictively since adolescents do not always easily accept these restrictions and also because these restrictions may limit young people's explorations of online opportunities. It seems more useful to support young people in their internet use so that they are able to cope properly with the online risks they will inevitably encounter while surfing the internet (Staksrud and Livingstone, 2009).

The purpose of this study is to get a better insight into the (risky) online activities of Flemish adolescents, to see how they cope with these online risks, and which factors have an influence on adolescents' online activities. First, we want to investigate the level of digital literacy among Flemish youth, and how this is influenced by socio-demographic and psychological factors. Second, we intend to find out to what extent Flemish adolescents are exposed to commercial, aggressive, sexual and/ or value-related content risks, and which adolescents are most vulnerable to exposure of these risks. Finally, we aim to learn more about the coping 
strategies young people use when confronted with online risks, and how parental mediation can influence their coping strategies.

Belgium is a "medium-risk" and "medium-use" country, just like Austria, Ireland, Portugal and Spain. As to the prevalence of online risks, Greece, Denmark and Sweden also belong to the group of medium-risk countries. As to children's internet use, France, Germany, Bulgaria and the Czech Republic are also characterized by a medium level of use (Livingstone and Haddon, 2009). For countries sharing characteristics with the Belgian situation it is interesting to investigate the influences of sociodemographics and personality traits. Moreover, this study may also be of interest for other countries, especially those combining "high risk" and "low use". For countries confronted with this delicate combination, it may be useful to investigate the situation in a medium-level country as a guiding principle in the development of policies on digital literacy and online risks.

\section{Theoretical background}

Livingstone and Haddon (2009) describe which online risks and opportunities young people may be exposed to as recipients (content), as participants (contact) and as actors (conduct). In this article, we focus on risks related to online content. Four different types of content risks are distinguished: commercial risks, aggressive risks, sexual risks and valuerelated risks. Commercial risks refer to the reception of spam and (unwanted) publicity. The exposure to violent or shocking content is what we call aggressive risks. Sexual risks allude to encountering pornographic material. Value-related risks are contents containing incorrect, value-loaded, and/or dangerous information and advice on themes such as racism, suicide or anorexia (see also Livingstone and Haddon, 2009). In this study, we use a child-centered approach. This means we see children as active online participants, with their own opinions and motivations. We investigate children's internet use from their own perspective and daily experiences, because we want to understand the importance and impact of the internet on children's lives.

Policymakers, researchers, and educators tend to focus on online risks. Nevertheless, the internet also offers a broad range of opportunities for young people as it is an endless source of information and an interesting playground for children. In a pleasant and playful way they can improve their information seeking strategies as well as sharpen their evaluating skills while searching for information. Thanks to the diversity of online resources, children are invited to be creative in their search strategies and to develop a critical attitude. Meanwhile, they learn about different points of view and how different communities and individuals partici- 
pate in society. Both educational purposes, needs for advice, personal interests and entertainment purposes can motivate a child to go online and search for content (Livingstone, 2008).

There is a need for more in-depth theoretical research in the field of digital literacy of young people. Only recently attention has been paid to the multiple layers within this concept. Digital literacy, including "internet literacy", is related to the concept of media literacy, which refers to the skills of an individual to collect, analyze, evaluate and create information (Livingstone, 2004). We define digital literacy as a concept with width and depth. On the one hand, we consider it as a range of capacities an individual has acquired to use ICT in order to obtain knowledge and information, to evaluate it critically, to select relevant elements, and to create new content. On the other hand, digital literacy refers to the type of internet use: more sophisticated use of the internet, such as creating content or participating actively in society through the internet, indicates a higher level of digital literacy (Livingstone and Helsper, 2007). The frequency of internet use, the use of online opportunities (the width of use of online applications), and self-perceived internet skills are indicators for an individual's level of digital literacy.

Different studies show that young people are far from a homogeneous group. Age, sex and socio-economic status of the parents turn out to be extraordinary strong indicators for trends in ICT use (Wartella et al., 2000). Contrary to all expectations, the internet does not operate as an equalizing factor, therefore it is deemed necessary to focus on the promotion of digital literacy and on adequate prevention of possible damaging use of internet applications. The lack of attention paid to the mutual digital divergences between groups of children and young people is the result of the optimistic rhetoric from Tapscott (1998) and others of the so-called digital generation. In this context, technophobia is generally associated with inflexibility and conservatism, while creativity and spontaneity are attributed to technophile children and young people.

Similar visions contrast sharply with empirical research showing a great amount of divergence in ICT use and skills between children and young people, even in cases of equal access to ICT. Age differences are generally seen as linear: over the years one displays a growing inclination to search for more online risks and chances. Differences in sex, SES and education are generally seen as strong, but not always as predictable (Weiser, 2000). In other words, digital literacy is a complex matter whereby, besides socio-demographic circumstances, also psychological factors (e.g., self-image, risk-perception) play a role (Broos and Roe, 2006). Taking into account this complexity, we will interpret the potential role of sociodemographics and personality traits in the use of digital technology within the framework of digital inclusion and the socialization theory. 
The binary definition of the digital gap (one is either in- or excluded) turned out to be a dead end. It makes much more sense to measure the gradations of digital inclusion by a continuum from basic users up to more sophisticated users. Van Dijk (2006) brings up for discussion whether unequal chances lead to the digital gap. He distinguishes between differences in material access and motivation and differences in skills and use. An example: although the gender-difference in access in North-Western Europe and North America has been eliminated, the socalled gender gap continues to exist because boys seem to be more likely than girls to use more complex online opportunities that require user interactivity and creativity. From this perspective, the "ladder of online opportunities" from Livingstone and Helsper (2007) is a useful analytical tool in order to work out the depth and width of the use of digital technology. Research shows that young people with a high level of digital literacy use more online opportunities, and as a result they also encounter more online risks. If one aims to develop into a skilled internet user, risk exposure seems to be inevitable.

The socialization theory stresses the importance of social and cultural values during childhood and adolescence brought about by three important socializing actors: family, school and friends. Values are determined for age and gender inside the family context; these values influence young people's behavior and the extent to which they conform to these values, also inspired by their peers.

Policy makers and educators continue to struggle in searching a balance between on the one hand protecting children against inappropriate online content, and on the other hand respecting the autonomy, privacy and freedoms of the child. Therefore, it is crucial to help children in acquiring strategies that help them coping with these online risks and reducing the possible harm of these online contents (Staksrud and Livingstone, 2009). The development of children's coping strategies can be influenced by the intervention style of their parents. Research indicates that parents who are frequent internet users and have a high level of digital literacy mediate the internet use of their children more intensively. Parents prefer social interventions such as talking about their child's internet use or sitting together at the computer instead of mere restrictive forms of mediation such as a prohibition to use certain applications or the installation of filtering and monitoring software (Livingstone and Helsper, 2008).

This theoretical background brings us to the following three research questions:

RQ 1: What is the state of the art of digital literacy of Flemish youth (15- to 19-year-olds)? To what degree do the current socio-demo- 


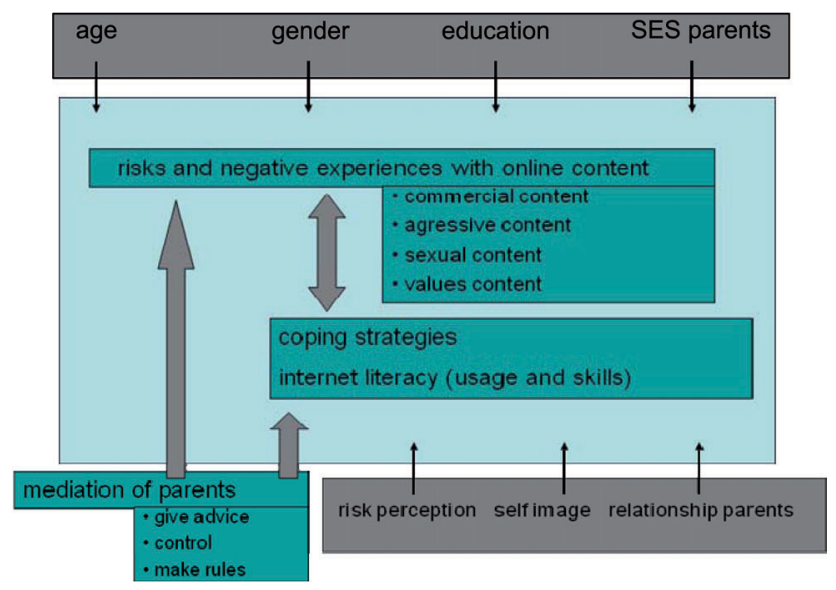

Figure 1. Research model.

graphic characteristics (age, gender, education, SES of the parents) and personality traits (self-image, risk perception, relation with parents) predict this digital literacy?

RQ 2: To what extent do socio-demographic and personality traits of Flemish young people predict the exposure to and experience of negative online content of commercial, aggressive, sexual or value-related nature?

RQ 3: Which coping strategies do Flemish young people use after exposure to risky online content? Do these strategies depend on the general risk perception of young people, their self-image or their relation with their parents? Does the style of parental intervention influence the coping strategies of young people?

Schematically, the above-mentioned research questions resulted in figure 1.

\section{Method and concepts}

\section{Data collection}

A written questionnaire was filled out by 815 Flemish youngsters in the third to sixth grade of secondary school in the Spring of 2009 (FebruaryApril). Nine Flemish schools across different regions participated in the survey. The number of respondents per school ranged from $29(3.5 \%)$ to 159 students (19.5\%). Our sample consisted of $50.1 \%$ boys and $49.9 \%$ girls with an average age of 16.57 years $(S D=1.24)$. Even though we 
Table 1. Different education levels in $\%$.

\begin{tabular}{lll}
\hline & $\begin{array}{l}\text { Respondents } \\
(N=815)\end{array}$ & $\begin{array}{l}\text { Students enrolled in Flemish schools in 2009 } \\
(N=290,856)\end{array}$ \\
\hline ASO & 50.8 & 40.7 \\
TSO & 36.3 & 32.3 \\
BSO & 12.9 & 24.9 \\
KSO & 0 & 2.1 \\
\hline
\end{tabular}

ASO: general secondary education; TSO: technical secondary education; BSO: vocational secondary education; KSO: arts secondary education

(Source: Ministry of Education, 2008)

initially aimed at a balanced sample in terms of the school type youngsters attended, students enrolled in vocational education (BSO) remained underrepresented (see table 1) (Ministry of Education, 2008).

\section{Digital literacy}

The level of digital literacy was measured by using:

1) the frequency of general internet use (five points scale from "less than once a week" to "several times a day");

2) the use of online opportunities, measured through the frequency of use of several online applications (nine items on a five points scale from "less than once a week" to "several times a day");

3) self-perceived internet skills, measured through the indication of whether or not the respondent is able to perform a range of online tasks (15 items on a dichotomous yes/no scale).

Concerning online opportunities (the use of online applications), we distinguish two types of use ( 7 items, factor analysis with Varimax rotation; $d f=21 ; p<0.001$ ) (Cronbach's $\alpha=0.67$ ):

1) The use of applications directed at active searching for entertainment and new/unknown content or contacts (downloading music, downloading films/series, chatting in chat rooms, playing games and posting photographs online);

2) The use of applications directed at communicating with known contacts (e-mailing and instant messaging).

The items "online shopping" and "searching information for school" were deleted from the analysis because they loaded on more than one factor. 
1) As regards self-perceived internet skills, we distinguish three types of skills (12 items, factor analysis with Varimax rotation; $d f=15$; $p<0.001$ ) (Cronbach's $a=0.76$ ), referring to knowledge of social communication applications (chatting with instant messengers, chatting with webcam, posting pictures, downloading music and images, subscribing on social networking site);

2) Knowledge about software (installing software, posting messages on forum, downloading software);

3) Knowledge about the possibilities to create content (building website, creating a blog, computer hacking).

The items "send an email", "type a letter" and "searching information" were deleted from analysis because they loaded on more than one factor.

\section{Online risks}

In their three C's risk model, Staksrud and Livingstone (2009) distinguish between content risks (child as recipient), contact risk (child as participant) and conduct risks (child as actor). In this article we only focus on content risks, i. e. risks related to the exposure to online content through websites, emails, chat conversations, etc. The respondents were asked to indicate if they had ever received unrequested emails with advertisements (commercial risks), if they had ever encountered pornographic material on a website (sexual risks), if they had ever encountered a violent website with gruesome pictures, and if they had ever encountered a racist or suicide website (value risks). In the question about spam, the respondents were asked to indicate their answer on a dichotomous yes/no scale. In the other questions, they were asked to indicate whether they had ever visited such a website, and if yes, how they had encountered the website (accidentally, on purpose, through junk-mail or through a link sent to them).

\section{Coping strategies}

Sooner or later, young people are exposed to risky online content. Their reactions to these (negative) experiences are diverse; they can either ignore the problem or face it. We investigate young people's reactions to these online risks: i.e. the strategies they use to cope with online risks and to protect themselves from potential harm caused by these risky contents. Young people can either take preventive measures, which means they anticipate and take precautions before they are actually exposed to risky online contents, such as installing a spam filter or they can decide to react (or not) after a negative experience. In the latter case 
they will take reactive measures, such as immediately leaving a potentially harmful website. Coping strategies can either be self-regulating or communicative. Self-regulating strategies do not involve others and include behaviors such as deciding whether or not to go back to a specific website. Communicative strategies involve discussing the (negative) experience with a peer and/or an adult.

Immediately after the question about encountering risky websites, the respondents were asked what they had done the last time they had been exposed to a potentially harmful website (options: leave the website, first take a look and then leave the website, return to the website on a later moment, forwarding the link, talk about the website with peers or an adult).

\section{Parental mediation}

Parents can mediate their children's internet use in different ways. In order to find out whether their parents mediate by either giving advice or by controlling their internet use, the respondents were given a list of seven items in which they were asked to indicate on a four point Likert scale whether their parents never, rarely, sometimes or often engaged in this activity. Two types of intervention styles were found ( 7 items, factor analysis with Varimax rotation; $d f=15 ; p<0.001$ ) (Cronbach's $a=0.66$ ):

1) Counselling intervention (show how to find interesting websites, teach how to use the internet, point out existing online risks).

2) Controlling intervention (limit the length of time, control the visited websites, and actively supervise while using the computer).

The item "my parents give me tips for better internet use" was deleted from the analysis because it loaded on more than one factor.

In order to find out if and how parents mediate restrictively, the respondents were presented a list of eight possible restrictions and were asked to indicate on a dichotomous yes/no scale if their parents had prohibited the use of any of applications included on the list. A factor analysis was conducted ( 8 items, factor analysis with Varimax rotation; $d f=21 ; p<0.001$ ) (Cronbach's $a=0.65$ ), and two different types of parental restrictions on internet use were found;

1) Restrictions on applications for contact and communication (prohibition to transmit personal information, to visit certain websites, to talk to strangers in chat rooms and to meet "face-to-face" with someone first met through the internet); 
2) Restrictions on entertainment applications (prohibition to download films/music, to play online games and to use the internet for nonschool related activities).

The item "I'm not allowed to buy things on the internet" was deleted because it loaded insufficiently.

\section{Results}

\section{Digital literacy}

The time Flemish 15- to 19-year-olds spend on the internet and more specifically on different internet applications was scrutinized: $76.4 \%$ use the internet daily or several times a day. Table 2 shows that among the internet uses, communication applications such as instant messaging and sending e-mails are the most popular. Entertainment applications such as online games (12.7\%) and downloading music (14.2\%) follow at a distance and the posting of photographs $(7.9 \%)$, downloading of films $(5 \%)$ and chatting in chatrooms $(5.8 \%)$ belong to the more peripheral activities.

As to self-perceived internet skills, three user types were identified (after factor analysis with Varimax rotation; $d f=66, p<0.001$, see methods section): skills in online social communication (79\%) and software skills $(74 \%)$, which are clearly more commonly present among adolescents than skills in content creation $(10 \%)$.

While searching for socio-demographic differences, we note that digital literacy of boys is higher $(M=3.6)$ than that of girls $(M=3.2)$ $(t=6.99 ; d f=800 ; p<0.001)$. Boys particularly score higher in the area of self-perceived software skills $(t=6.68 ; d f=713,6 ; p<0.001)$ and skills in content creation $(t=573, d f=795.8 ; p<0.001)$. The

Table 2. Frequency of internet applications in $\%(N=805)$.

\begin{tabular}{lcccrc}
\hline & $\begin{array}{c}<\text { once } \\
\text { a week }\end{array}$ & $\begin{array}{c}\text { Once } \\
\text { a week }\end{array}$ & $\begin{array}{c}>\text { once } \\
\text { a week }\end{array}$ & Daily & $\begin{array}{c}>\text { once } \\
\text { a day }\end{array}$ \\
\hline Sending e-mail & 9.4 & 7.1 & 31.4 & 38.8 & 13.3 \\
Online shopping & 96.0 & 2.2 & 1.0 & 0.6 & 0.3 \\
Search information for school & 24.6 & 25.3 & 40.4 & 7.6 & 2.1 \\
Downloading music & 26.3 & 20.0 & 31.9 & 14.2 & 7.6 \\
Downloading film/series & 68.9 & 10.4 & 12.0 & 5.0 & 3.6 \\
Instant messaging & 14.3 & 5.9 & 25.6 & 31.5 & 22.7 \\
Chatting in chat rooms & 74.1 & 7.1 & 7.8 & 5.8 & 5.3 \\
Play games & 40.2 & 17.7 & 21.0 & 12.7 & 8.4 \\
Posting photos online & 50.4 & 23.0 & 16.6 & 7.9 & 2.0 \\
\hline
\end{tabular}


digital literacy of Flemish young people increases with age $(F=6.36$; $d f=1 ; p<0.05)$. This is reflected in the possession of more self-perceived software skills $(F=11.08 ; d f=1 ; p<0.001)$. Teenagers in vocational training show a significantly lower digital literacy level $(M=3.1)$ than their peers from general education $(M=3.4)$ and technical education $(M=3.5)(d f=2 ; p<0.001)$. Thus, young people enrolled in vocational education (BSO) have significantly less self-perceived skills of applications in the field of online social communication than young people attending grammar schools (ASO) $(M D=0.08 ; S E=0.02 ;$ sig $=0.001)$ and from technical education $(M D=0.08 ; S E=0.02 ; \mathrm{sig}=0.003)$. An identical trend can be observed concerning self-perceived software skills: vocational education-pupils report less software skills compared to those enrolled in technical education $(M D=0.16 ; S E=0.04 ;$ sig $=0.000)$ and in grammar schools $(M D=0.16 ; S E=0.04 ;$ sig $=0.000)$. As to skills in content creation, pupils enrolled in technical education estimate their self-perceived skills higher than that of their peers in grammar school $(M D=0.07 ; S E=0.02 ; \mathrm{sig}=0.009)$. Neither the educational level, nor the profession of the father or the mother are associated with the level of digital literacy of their children; the profession of the father is insofar determinant that when the father is unemployed, the group of sons and daughters with an average or lower literacy level is bigger $(6.1 \%)$ than when the father does work $(43.4 \%)$, regardless of the profession. As to self-perceived skills on the three areas under study (applications for online social communication, software and content creation), the profession and education of the parents has no influence.

When further analysing the use of online opportunities (the use of different applications), we find that boys are more fervent users of technologies that have an entertaining function than girls $(t=7.16$; $d f=769.7 ; p<0.001)$. Age does not play a role in this case. Concerning the use of applications to communicate with familiar persons, we observe no significant gender differences. Age does have an impact here: as children grow older, they employ applications that support communication more often $(F=5.16 ; d f=1 ; p<0.05)$. Educational level also turns out to be of great influence: pupils enrolled in grammar school make use of entertainment applications less often $(M D=0.25 ; S E=0.10 ;$ sig $=0.027)$, but use applications for communication with familiar persons more often in comparison to their peers from vocational education $(M D=$ 0.33; $S E=0.12 ; s i g=0.022$ ). Profession and education of the parents do not play a significant role in the use of entertainment applications. Variation in the use of technology for communication purposes with mainly familiar persons does depend on the father's profession $\left(X^{2}=\right.$ $25.4 ; d f=8 ; p<0.001)$. In the case of the father being unemployed, the son or daughter tends to make less use of technology for practical 
communication aimed at familiar persons than their peers with working parents. Young people with semi- and unskilled parents make significantly less use of technology for practical communication purposes with familiar contacts than their peers with highly-educated parents $(M D=$ $0.36 ; S E=0.14 ; \operatorname{sig}=0.040$ ).

When it comes to personality traits, the level of digital literacy of Flemish teenagers shows a positive correlation with their self-image/ confidence $(F=11.4 ; d f=1 ; p<0.001)(7$ items, Cronbach's $\alpha=0.81)$ (items were scored on a 5 point Likert-scale from 'totally not agree' to 'totally agree'). Young people with a positive self-image and high selfconfidence make significantly more use of technology for entertainment and new contacts $(F=14.1 ; d f=1 ; p<0.001)$ and indicate a higher level of self-perceived skills in content creation $(F=3.7 ; d f=2$; $p<0.05$ ). Applications directed at existing contacts do not show a different use depending on self-image/confidence. The diversity in perceiving the internet as a safe environment and the degree to which one is worried about security on the internet does not influence the level of digital literacy. Neither does the relation with the parents, finally, influence digital literacy of Flemish teenagers demonstrably. A good relation with the parents, however, is related to a lesser degree of use of applications for entertainment or potentially risky new contacts, compared to young people who have a bad $(M D=0.38 ; S E=0.12 ; \mathrm{sig}=0.010)$ or normal relationship with their parents $(M D=0.14 ; S E=0.05$; sig $=0.023)$.

In sum, we conclude that girls and vocational education students show a lower overall level of digital literacy. When taking a closer look at different types of internet use, we note that boys, students enrolled in vocational education, teenagers with high-self confidence and those having a bad relationship with their parents, are more focused on using entertainment applications. Older teenagers (18-19 years old), general education students and children from affluent households have on their turn stronger preferences towards communication applications.

\section{Online risks}

The majority of young people (84.3\%) regularly or frequently come into contact with commercial risks. About six out of ten young people regularly or frequently come into contact with sexual content. For those who run into pornography, this happens on a (very) regular basis in the majority of cases. Exposure to aggressive content happens less frequently: about three out of ten young people are regularly confronted with aggressive content while about one out of ten is frequently confronted with it. As frequent exposure is rather limited, we can assume that the impact 
Table 3. Exposure to different types of risks.

\begin{tabular}{llllc}
\hline & $\begin{array}{l}\text { Commercial } \\
\text { risks } \\
(M=2.1)\end{array}$ & $\begin{array}{l}\text { Aggressive } \\
\text { risks } \\
(M=1.5)\end{array}$ & $\begin{array}{l}\text { Sexual } \\
\text { risks } \\
(M=2.0)\end{array}$ & $\begin{array}{l}\text { Value- } \\
\text { related risks } \\
(M=1.2)\end{array}$ \\
& $(S D=0.64)$ & $(S D=0.66)$ & $\begin{array}{l}(S D=0.88) \\
(S D=0.51)\end{array}$ \\
\hline $\begin{array}{l}\text { None/few exposure } \\
\text { Average exposure }\end{array}$ & $128(15.7 \%)$ & $488(59.9 \%)$ & $316(38.8 \%)$ & $675(82.8 \%)$ \\
Much exposure & $209(25.6 \%)$ & $74(9.1 \%)$ & $319(39.1 \%)$ & $38(4.7 \%)$ \\
\hline Total & $815(100 \%)$ & $815(100 \%)$ & $815(100 \%)$ & $815(100 \%)$ \\
\hline
\end{tabular}

of aggressive content on attitudes with respect to aggression remains small. Nevertheless, possible negative impact of such exposure cannot be simply discarded and needs to be further studied. Contact with valuerelated risks is relatively rare. More than 8 out of 10 young people have never or almost never been confronted with it (see table 3).

Boys are exposed significantly more often to all types of risks than girls. The differences are more explicit in the case of aggressive content $(t=18.1 ; d f=730.95 ; p<0.001)$ and of sexual content $(t=16.8$; $d f=791.05 ; p<0.001)$. Older teenagers, in particular 18- to 19-yearolds, are more frequently exposed to sexual $(F=21.9 ; d f=1 ; p<0.001)$ $(M D=0.42 ; S E=0.07 ;$ sig $=0.000)$ and value-related contents $(F=5.8 ; d f=1 ; p<0.050)(M D=0.15 ; S E=0.06 ;$ sig $=0.037)$, compared to the younger age groups. Young people of technical education encounter significantly more often aggressive $(F=70.94 ; d f=2$; $p<0.001)$, sexual $(F=10.10 ; d f=2 ; p<0.001)$ and value-related risks (Welch $=6.3 ; d f=266.9 ; p<0.01$ ). The difference in exposure between pupils of technical education and other education levels are most pronounced in aggressive and sexual contents. We hereby observe that young people, especially boys, from technical education have a stronger self-image $\left(X^{2}=25.9 ; d f=4, p<0.001\right)$ and have a higher degree of digital literacy $\left(X^{2}=29.4 ; d f=4 ; p<0.001\right)$. Such online active young people, with a relatively high degree of self-perceived internet skills, encounter all types of online risks more often, be it of commercial $(F=20.8 ; d f=2 ; p<0.001)$, aggressive $($ Welch $=31.3 ; d f 1=2$; $d f 2=80.4 ; p<0.001)$, sexual $(F=22.4 ; d f=2 ; p<0.001)$ or valuerelated nature $($ Welch $=12.4 ; d f 1=2 ; d f 2=82 ; p<0.001)$. This indicates that intensive internet activity goes together with more exposure to online risks.

Children of parents with a lower level of education come into contact more often with aggressive $(F=4.5 ; d f=2 ; p<0.050)(M D=0.21$; $S E=0.07 ; \operatorname{sig}=0.008)$, sexual $(F=3.1 ; d f=2 ; p<0.05)(M D=0.28$; 
$S E=0.11 ;$ sig $=0.041)$ and value-related contents $($ Welch $=6.8$; $d f 1=2 ; d f 2=130.9 ; p<0.01)(M D=0.38 ; S E=0.11 ; \operatorname{sig}=0.002)$. We find that children of lower educated parents often have either a strong self-image or a low self-image $\left(X^{2}=32.9 ; d f=4 ; p<0.001\right)$ and furthermore maintain a rather bad relationship with their parents $\left(X^{2}=54.2 ; d f=4 ; p<0.001\right)$. Young people who are self-confident, have more contact with aggressive content on the internet $(F=5.7$; $d f=2 ; p<0.01)$ as well as with sexual contents $(F=8.1 ; d f=2$; $p<0.001)$. As to value-related contents $($ Welch $=4.7 ; d f 1=2$; $d f 2=64 ; p<0.050$ ), we note that young people with a normal selfimage have less contact with such contents. When the relation with their parents is good, young people encounter less aggressive (Welch $=8.6$; $d f 1=2 ; d f 2=179.9 ; p<0.001)$ sexual $(F=3.6 ; d f=1 ; p<0.050)$ and value-related contents $($ Welch $=14.6 ; d f 1=2 ; d f 2=175.9 ; p<0.001)$. A good parent-child relationship is unrelated to whether they actively intervene in the internet use of their children or not, but it seems to reduce their children's contacts with online risks.

\section{Strategies to cope with online risks}

We find that young people generally choose preventive/self-regulating strategies when coping with online risks (see Table 4). The large majority of young people $(83.2 \%)$ will use average to strong preventive strategies by, e.g., not responding to e-mails containing publicity and by being critical towards companies/organizations asking for personal data.

Reactive and self-regulating strategies are mostly used in a limited fashion: i.e. only some of the given strategies are used. When young people come in contact with unwanted contents, $32 \%$ (suicide) to $42 \%$ (violence) of them will (just) look at the website and then leave it perma-

Table 4. Use of different types of strategies

\begin{tabular}{llllll}
\hline $\begin{array}{l}\text { Preventive/ } \\
\text { self- } \\
\text { regulating }\end{array}$ & $\begin{array}{l}\text { Frequency } \\
(\%)\end{array}$ & $\begin{array}{l}\text { Reactive/ } \\
\text { self- } \\
\text { regulating }\end{array}$ & $\begin{array}{l}\text { Frequency } \\
(\%)\end{array}$ & $\begin{array}{l}\text { Reactive/ } \\
\text { communicative }\end{array}$ & $\begin{array}{l}\text { Frequency } \\
(\%)\end{array}$ \\
\hline $\begin{array}{l}\text { Limited } \\
\text { coping }\end{array}$ & $135(16.8 \%)$ & No coping & $63(16.6 \%)$ & No coping & $362(46.2 \%)$ \\
$\begin{array}{l}\text { Average } \\
\text { coping }\end{array}$ & $417(51.9 \%)$ & $\begin{array}{l}\text { Limited } \\
\text { coping }\end{array}$ & $262(68.9 \%)$ & $\begin{array}{l}\text { Limited } \\
\text { coping }\end{array}$ & $313(39.9 \%)$ \\
$\begin{array}{l}\text { Strong } \\
\text { coping }\end{array}$ & $251(31.3 \%)$ & $\begin{array}{l}\text { Average/ } \\
\text { strong coping }\end{array}$ & $55(15.5 \%)$ & $\begin{array}{l}\text { Average/ } \\
\text { strong coping }\end{array}$ & $109(13.9 \%)$ \\
\hline Total & $803(100 \%)$ & & $380(100 \%)$ & $784(100 \%)$ \\
\hline
\end{tabular}


nently. About 20\% (suicide) till 28\% (violence and racism) of the young people will leave the website immediately. Strategies such as going back to the website, forwarding the link/photo to others occurs less frequently (less than $10 \%$ ).

Young people are less inclined to talk with others about negative experiences on the internet. Less than half (46.2\%) never talk about it to anyone. Very few young people engage in a conversation with adults: this varies from $9.3 \%$ on racism to $13.1 \%$ who will talk about pornography with parents and/or teachers. Experiences with pornography are mainly shared with peers $(44 \%)$. There is noticeably less talk on other risky contents such as violence $(12.4 \%)$, racism $(11.2 \%)$ and suicide $(8.3 \%)$ among peers.

The risk perception seems to have an impact only on the use of prevention/self-regulating strategies. Young people with a low risk perception are more inclined to use preventive/self-regulating strategies $(F=6.7 ; d f=2 ; p<0.050)$. When the relation with the parents is bad, young people use more reactive/self-regulating strategies $(F=3.0$; $d f=2 ; p<0.050)(M D=0.11 ; S E=0.45 ;$ sig $=0.048)$. This means that, in comparison with young people with a good parental relationship, they will more often take independent measures in order to be able to cope better with unwanted content, without engaging in conversations about it. Furthermore, we note that young people with a rather bad parent-child relationship will more often turn to teachers to talk about bad online experiences than young people who are on good terms with their parents $\left(X^{2}=26.4 ; d f=2 ; p<0.001\right)$.

\section{Parental mediation}

Parents can act in an advisory, controlling or restrictive way concerning the internet use of their children. Children of parents who would hardly ever give advice $(M=2.4 / S D=0.63)$ are inclined to choose more preventive/self-regulating strategies than children who get a lot or an average amount of advice $(M=2.2 / S D=0.66)(t=2.1 ; d f=800$; $p<0.050)$. When looking at communicative strategies, it seems that a controlling attitude only has influence on talking about violence, racism or suicide on the internet $\left(X^{2}=4.9 ; d f=1 ; p<0.050\right)$. Moreover, this only concerns communication with peers $\left(X^{2}=5.0 ; d f=1 ; p<0.050\right)$, which means that children who are being heavily controlled by their parents tend to tackle this problem more often with their peers than with parents or teachers. When parents hardly lay down any rules concerning the use of internet for (social) contacts, their children will easily take the step to talk about risky contents on the internet with their peers $\left(X^{2}=6.5 ; d f=1 ; p<0.050\right)$. This concerns only pornographic sites 
$\left(X^{2}=4.9 ; d f=1 ; p<0.050\right)$. When parents impose an average amount to a lot of rules concerning the use of internet for entertainment, children will more often talk to adults concerning (negative) internet experiences $\left(X^{2}=5.7 ; d f=1 ; p<0.050\right)$. This counts only for websites containing violence, racism or suicide $\left(X^{2}=8.05 ; d f=1 ; p<0.010\right)$.

\section{Discussion and conclusion}

A more intensive use, a broader use of internet opportunities, and a higher level of (self-perceived) internet skills entail a potentially higher exposure to all types of online risks. This can possibly explain why Flemish boys and the older age-group members of 18 to 19 year-olds are noticeably more prone to internet risks than girls and younger teenagers. The role of self-image is remarkable: self-confident teenagers make more use of the internet in order to discover new things and consequently experience more exposure to risky contents. These young people have possibly a strong need to defy themselves by exposing themselves to potentially offensive content. The degree of self-confidence is higher among boys and pupils enrolled in technical education (TSO): they turn out to be more active on the internet and to be more often exposed to internet risks than girls and pupils from general or vocational schools. Hence, parents should invest in a relationship based on trust with their sons and daughters: after all, teenagers with a good relationship with their parents are less active regarding the use of entertainment applications (although the potentially positive cognitive impact of these applications should not be underestimated), they come in contact less often with risky contents, and they do not make as many new and therefore potentially risky contacts through the internet.

Flemish teenagers of the lower socio-economic families and pupils in vocational education use technology less to maintain or promote their social contacts. Thus, teenagers who already have fewer possibilities regarding social contacts and who have restricted study capacities also make the least use of technology in order to make contacts. Still, we find that children of unskilled parents experience more exposure to potentially risky contents. In contrast with this general trend, we find that in less affluent families low use goes hand in hand with high risks. Unskilled parents are often less acquainted with computers and the internet. This can lead to more insecurity concerning adjustment and guidance of internet use of their children and to an underestimation of the online risks their children may be confronted with.

Flemish young people are mostly exposed to commercial risks. Sociodemographics and personality traits have very little impact on this. These circumstances exhibit an average to strong coherence with the exposure 
to aggressive, sexual and value-related contents. Commercially tinted contents are generally less offensive, which is why young people may not realize at once that they possibly run real privacy and/or financial risks. More frequent exposure can therefore become more probable. As to pornography, it seems that a first contact with pornographic material will often result in frequent exposure. After a first contact with pornographic material, young people may either go looking consciously for more pornography, or pornographic images may after that appear (unsolicited) on the screen through pop-ups or spam.

Most young people employ a certain amount of preventive strategies in order to protect themselves against possible internet risks. Especially young people who receive little advice at home and perceive the internet as safe seem to take preventive action more often. Reactive measures are taken only seldom. Young people are (very) rarely inclined to communicate with others about encounters with risky contents, except when it concerns talking about pornography with peers. It is striking that the self-image does not seem to have any impact on the use of strategies in order to cope with internet risks. Young people who have a bad relationship with their parents seem to take more action after encountering risky contents in order to avoid exposure in the future. It is possible that these young people have a more independent attitude in other situations as well; as they do not feel that they can expect the desired help from their parents and will therefore take quicker action whenever a problem occurs. The mediation of the parents has no univocal impact on the strategies children will apply in order to learn how to cope with internet risks. Depending on the nature of risks (pornography, violence, racism or suicide), young people apply very different communication strategies, e.g., when parents do not make rules about the internet use for (social communication), children tend to talk more often with peers about porn but not about other types of content.

In an information society, a substantial level of digital inclusion is crucial in order to be able to actively participate in society. Hence, it is important to encourage young people to explore the broad range of opportunities and benefits the internet has to offer. By doing this, they can evolve from children who only look for information or play online computer games to adolescents who actively participate in online discussions and write down their opinions and arguments on their blogs or websites. These steps towards a more complex internet use will only be possible if adolescents develop not only their capacity to select online contents, but above all to critically evaluate the contents they encounter online and to become aware of possible online risks associated with them. Such attitudes will help children and young people to develop 
more appropriate strategies to cope with potentially harmful contents and to avoid damaging exposure in the future.

We conclude that digital inclusion among Flemish adolescents is a gradual process; young people are more skilled in applications for information gathering, entertainment and communication than in applications aimed at content creation. The importance of the social environment (socialization theory) results from the impact of the quality of the parent-child relationship. Since parental mediation does not lead to similar results concerning their children's exposure to online risks, we conclude that parents with more socio-economic capital are more involved in their children's internet use. Also, the level of parental mediation decreases as the child grows older.

A limitation of this research is the small subsample of young people enrolled in vocational education. Nevertheless, we consider our explorative findings to be related to vocational education students as relevant especially because of the "at-risk" nature of this population group. Further research on the basis of a representative sample is thus required. Secondly, certain strategies for coping with internet risks, especially communicative strategies, are applied by only a small group of young people. In the future, a sample survey with a more balanced sample composition will be necessary in order to be able to further interpret these findings. Concerning the measurement of preventive/self-regulating strategies, more specific questions are necessary with a focus on aggressive, sexual and value-related risks. Third, no conceptual model was developed and tested in this explorative study. In further research about this topic we plan to conduct multivariate analysis, which should provide us with a deeper insight into mediating relationships between the factors involved. The present limitations will be overcome in a cross-country research planned in the Spring of 2010 within the scope of the EU Kids Online II-survey on the basis of face-to-face surveys to be conducted among 25,000 children and their parents in 24 different European countries and Turkey. The first data analysis are to be expected in the Fall of 2010.

\section{Bionotes}

Sofie Vandoninck is Research assistant at the Center for Media Culture and Communication Technology, K.U. Leuven, Belgium.

Leen d'Haenens is Professor at the Center for Media Culture and Communication Technology, K.U. Leuven, Belgium.

Verónica Donoso is post doc researcher at MIOS (Media \& JCT in organizations an society), Department of Communication Studies of the University of Antwerp, and she is a research fellow at the Center for Media Culture and Communication Technology, K.U. Leuven, Belgium. 


\section{Notes}

1. We acknowledge the collaboration of Marlies Cumps, Jana Nauwelaerts, Evelien Van Gael, Steffi Van Schevensteen and Tina Wyns, who collected these school survey data for their MD theses.

2. This setting is based on the following typology of Internet use, developed by Tsatsou et al. (2009) on behalf of the EU Kids Online Project I in 21 countries of the EU:

High Internet use: countries where more than $85 \%$ of the children make use of the Internet (among others Denmark, Estonia, Finland, The Netherlands, Sweden, Great Britain, Poland, Slovenia and Norway).

Medium Internet use: countries where between $65 \%$ and $85 \%$ of the children are online (among others Austria, Belgium, Bulgaria, Czech Republic, France, Germany, Ireland, Iceland, Portugal and Spain).

Low Internet use: $\quad$ countries where less than $65 \%$ of the children have used Internet (among others Italy, Cyprus and Greece).

\section{References}

Broos, A., \& Roe, K. (2006). The digital divide in the playstation generation: selfefficacy, locus of control and ICT-adoption among adolescents. Poetics, 34(4/5), 306-317.

Department of Education (2008). Statistisch jaarboek van het Vlaams Onderwijs, schooljaar 2007-2008. [Statistical yearbook of Flemish Education, academic year 2007-2008]. Flemish Ministry of Education.

European Commission (2008). Towards a safer use of the internet for children in the EU - a parent's perspective. Flash Eurobarometer Series 248. Luxembourg: European Commission.

Livingstone, S. (2004). Media literacy and the challenge of new information and communication technologies. Communication Review, 1(7), 3-14.

Livingstone, S., \& Helsper, E. J. (2007). Gradations in digital inclusion: children, young people and the digital divide, New Media and Society, 9(4), 671-696.

Livingstone, S. (2008). Internet literacy: Young people's negotiation of new online opportunities. In T. McPherson (Ed.), Digital youth, innovation, and the unexpected (pp. 101-122). Cambridge, MA: The MIT Press.

Livingstone, S. \& Helsper, E.J. (2008). Parental mediation of children's internet use. Journal of Broadcasting and Electronic Media, 52(4), 581-599.

Livingstone, S., \& Helsper, E. (2009). Balancing opportunities and risks in teenagers' use of the internet: the role of online skills and internet self-efficacy. New Media and Society, 11(8), 1-25.

Livingstone, S., \& Haddon, L. (2009). EU Kids Online. Final Report. LSE, London: EU Kids Online.

Staksrud, E., \& Livingstone, S. (2009). Children and online risk. Powerless victims or resourceful participants? Information, Communication and Society, 12(3), 364-387.

Tapscott, D. (1998). Growing Up Digital: The rise of the net generation. New York, NY: McGraw-Hill.

Tsatsou, P., Pruulmann-Vengerfeldt, P., \& Murnu, M.F. (2009). Digital divides. In S. Livingstone \& L. Haddon (Eds.), Kids Online. Opportunities and risks for children (pp. 107-119). Bristol: The Policy Press/University of Bristol. 
Vandercammen, M. (Ed.) (2006). Jongeren en de nieuwe technologieën. [Young people and new technologies]. Brussels: OIVO.

Van Dijk, J. (2006). Digital divide research, achievement and shortcomings. Poetics, 34(4/5), 221-235.

Wartella, E. A., O'Keefe, B., \& Scantlin, R. (2000). Children and Interactive media. A compendium of current research and directions for the future. New York: Markle Foundation.

Weiser, E. B. (2000). Gender differences in internet use patterns and internet application preferences, CyberPsychology and Behavior 3(2), 167-177. 
Copyright of Communications: The European Journal of Communication Research is the property of De Gruyter and its content may not be copied or emailed to multiple sites or posted to a listserv without the copyright holder's express written permission. However, users may print, download, or email articles for individual use. 